\title{
Practical Approach to Initiating SGLT2 Inhibitors in Type 2 Diabetes
}

\author{
Fernando Gomez-Peralta $\cdot$ Cristina Abreu $\cdot$ Albert Lecube $\cdot$ \\ Diego Bellido · Alfonso Soto · Cristóbal Morales · Miguel Brito-Sanfiel • \\ Guillermo Umpierrez
}

Received: April 25, 2017 / Published online: July 18, 2017

(c) The Author(s) 2017. This article is an open access publication

\begin{abstract}
Sodium-glucose co-transporter 2 (SGLT2) inhibitors are an attractive novel therapeutic option for the treatment of type 2 diabetes. They block the reabsorption of filtered glucose in kidneys, mainly in proximal renal tubules, resulting in increased urinary glucose excretion and

This article has associated CME accreditation, valid until July 2018. Please follow this link to access the activity: https://diabetes.medicinematters.com/journal-articlecme.
\end{abstract}

Enhanced content To view enhanced content for this article go to http://www.medengine.com/Redeem/ 8A98F06056D16A6F.

F. Gomez-Peralta $(\bowtie) \cdot$ C. Abreu

Endocrinology and Nutrition Unit, Segovia General

Hospital, Segovia, Spain

e-mail: fgomezp@saludcastillayleon.org

\section{A. Lecube}

Endocrinology and Nutrition Unit, Hospital

Universitari Arnau de Vilanova de Lleida, Institut de

Recerca Biomèdica de Lleida, CIBERDEM (CIBER de

Diabetes y Enfermedades Metabólicas Asociadas,

ISCIII), University of Lleida, Lleida, Spain

D. Bellido

Endocrinology and Nutrition Section, Hospital

Marcide, Ferrol, Spain

A. Soto

Endocrinology and Nutrition Department, Hospital

de La Coruña, A Coruña, Spain correction of the diabetes-related hyperglycemia. Beyond improving glucose control, SGLT2 inhibitors offer potential benefits by reducing body weight and blood pressure. On the basis of the efficacy demonstrated in clinical trials, SGLT2 inhibitors are recommended as second- or third-line agents for the management of patients with type 2 diabetes. Beneficial effects on kidney disease progression, cardiovascular and all-cause mortality, and hospitalization for heart failure have also been demonstrated with one SGLT2 inhibitor (empagliflozin). Potential adverse events resulting from their mechanism of action or related to concomitant therapies are reviewed. A treatment algorithm for the adjustment of

\section{Morales}

Endocrinology and Nutrition Department, Virgen

Macarena Hospital, Seville, Spain

\section{Brito-Sanfiel}

Endocrinology and Nutrition Department, Hospital Universitario Puerta de Hierro Majadahonda,

Madrid, Spain

G. Umpierrez

Department of Medicine, Emory University School of Medicine, Atlanta, GA, USA 
concomitant therapies after initiating SGLT2 inhibitors is also proposed.

Keywords: Concomitant;

Initiation; Management; SGLT2 inhibitors; Type 2 diabetes

\section{INTRODUCTION}

Type 2 diabetes mellitus (T2DM) is a chronic metabolic condition characterized by a hyperglycemic state due to impaired insulin secretion and diminished insulin action in peripheral tissues [1]. Diabetes is the leading cause of blindness, non-traumatic limb amputations, and chronic kidney disease. It is strongly associated with an increased risk of life-threatening cardiovascular complications, such as myocardial infarction or stroke. Achieving optimal glycemic control remains a challenge due to several obstacles: the pathophysiology of diabetes, involving multiple deficiencies and/or resistances; low treatment adherence; clinical inertia; and resistance to implementing behavioral and lifestyle changes [2]. Adverse events (AEs), such as hypoglycemia or weight gain, also contribute to the challenge [3]. Traditional therapeutic approaches have been characterized by stimulating insulin secretion and/or improving peripheral insulin resistance. Sodium-glucose co-transporter 2 (SGLT2) inhibitors (dapagliflozin, canagliflozin, and empagliflozin in the USA and Europe, and ipragliflozin, luseogliflozin, and tofogliflozin in Japan) are a novel and attractive therapeutic approach for the treatment of T2DM [4].

\section{PHYSIOLOGICAL ACTION OF SGLT2 INHIBITORS}

SGLT2 inhibitors treat T2DM by selectively blocking SGLT2, a high capacity and low affinity glucose transporter expressed mainly in the S1 and S2 segments of the proximal tubule, inhibiting glucose reabsorption, lowering the renal glucose threshold, and inducing urinary glucose elimination (Fig. 1) [5]. SGLT2 activity seems to be upregulated in patients with T2DM, thereby increasing the renal glucose threshold and exacerbating the tendency to hyperglycemia. Inhibiting SGLT2 activity is accompanied by glycosuria and osmotic diuresis. Despite the fact that SGLT2 activity accounts for up to $90 \%$ of renal glucose reabsorption, in clinical practice SGLT2 inhibitors only block $30-50 \%$ of the filtered glucose load, even at higher doses [6]. An excess of 40-80 g of glucose and 200-600 mL urine per day are reported with the chronic administration of SGLT2 inhibitors [6]. Dosing and glomerular filtration rate cutoffs for SGLT2 inhibitors are shown in Table 1. The therapeutically induced glycosuria and osmotic diuresis lead to reductions in plasma glucose, body weight, and systolic and diastolic blood pressure [7]. These collateral effects are potentially beneficial because they may reduce the development of microvascular and macrovascular complications. On the basis of the efficacy demonstrated in clinical trials, SGLT2 inhibitors are recommended as second- or third-line agents for the management of patients with T2DM [8]. This article is based on previously conducted studies and does not involve any new studies of human or animal subjects performed by any of the authors.

\section{CLINICAL EFFICACY}

In randomized phase 2 and 3 clinical trials, the use of SGLT2 inhibitors as monotherapy (only indicated when intolerance to metformin or side effects exist) has been shown to significantly improve glycemic control in patients with T2DM. A systematic review of 45 randomized clinical studies comparing SGLT2 inhibitors to placebo $(11,232$ patients implicated) and 13 studies comparing SGLT2 inhibitors to active comparators (5175 patients using metformin, sitagliptin, or sulfonylurea) reported a reduction in $\mathrm{HbA} 1 \mathrm{c}$ of $-0.66 \%(95 \%$ confidence interval (CI) $-0.73 \%$ to $-0.58 \%)$ compared with placebo and $-0.06 \%(95 \% \mathrm{CI}$ $-0.18 \%$ to $0.05 \%)$ with respect to active comparators [7]. Greater HbA1c reductions $(0.44 \%$, $0.54 \%$, and $1.01 \%$ ) have been observed in patients with high baseline HbA1c levels, i.e., HbA1c less than $8.0 \% \quad(64 \mathrm{mmol} / \mathrm{mol})$, 


\section{Type 2 diabetic patient}

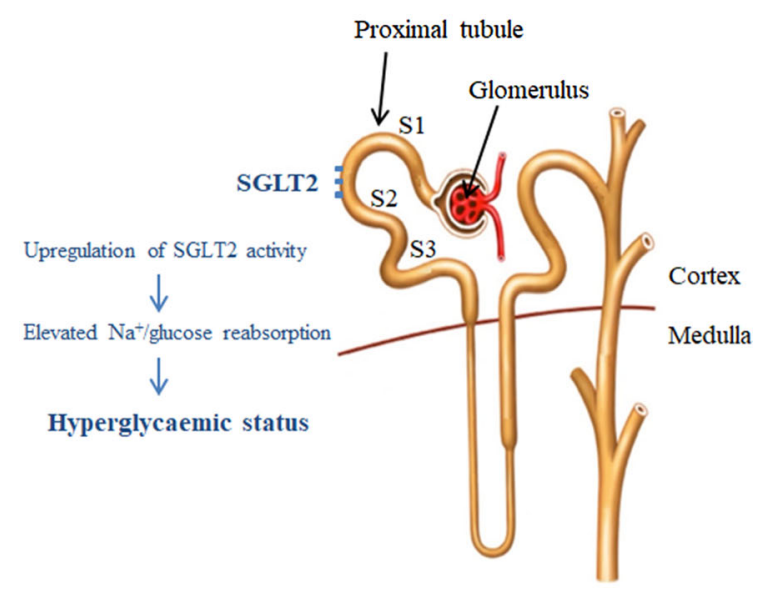

Type 2 diabetic patient receiving SGLT2 inhibitors

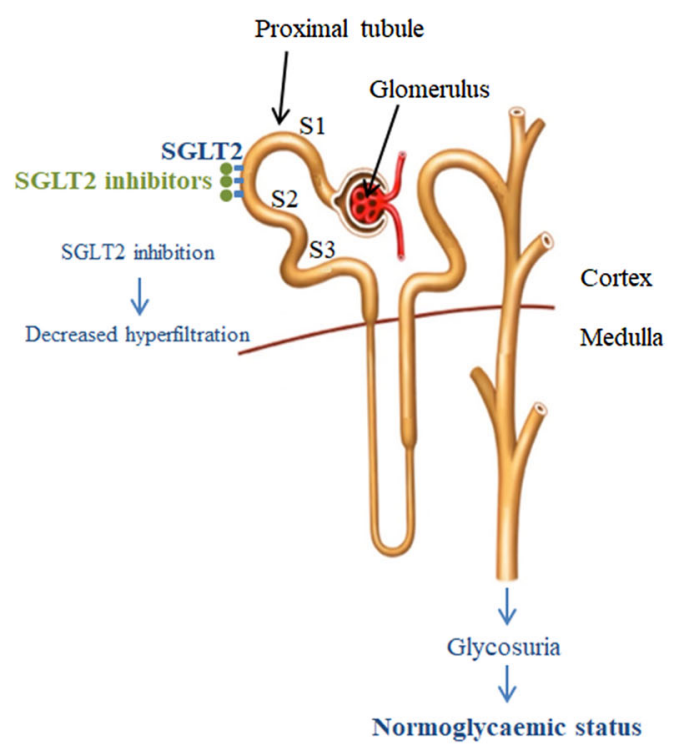

Fig. 1 Renal hyperfiltration in type 2 diabetes patients and the impact of receiving SGLT2 inhibitors. Modified from Fioretto et al. [5]. SGLT2 sodium-glucose co-transporter 2

HbA1c $=8.0-9.0 \% \quad(64-75 \mathrm{mmol} / \mathrm{mol}), \quad$ and HbA1c greater than $9.0 \% \quad(75 \mathrm{mmol} / \mathrm{mol})$, respectively [9]. In addition, SGLT2 inhibitor therapy as monotherapy or in combination with metformin has been described to induce stable weight loss $[10,11]$. In a systematic review, in comparison with other agents, SGLT2 inhibitors reduced mean body weight by $-1.80 \mathrm{~kg}(95 \% \mathrm{CI}-3.50$ to $-0.11 \mathrm{~kg})$ [7]. In this vein, SGLT2 inhibitors have also been associated with a reduced systolic blood pressure of $-4.45 \mathrm{mmHg}$ (95\% CI -5.73 to $-3.18 \mathrm{mmHg})$ from baseline. A meta-analysis involving 27 randomized clinical trials and 12,960 individuals (follow-up period ranging from 4 to 52 weeks) recently demonstrated that SGLT2 inhibitors achieve a reduction of systolic and diastolic blood pressure of -4.0 and $-1.6 \mathrm{mmHg}$, respectively [12]. Finally, the EMPA-REG OUTCOME trial, which aimed to evaluate long-term effects of empagliflozin on renal and cardiovascular outcomes in T2DM patients (3.1 years of median follow-up period), has demonstrated that, in addition to standard care, empagliflozin reduced the rate of incident or worsening nephropathy (approximately 39\% reduction), serum creatinine doubling (44\%), initiation of renal replacement therapy (55\%), the risk of death from cardiovascular disease (38\%), hospitalization for heart failure (35\%), and all-cause death (32\%) in patients with T2DM and high cardiovascular risk [13, 14]. Separation of event curves started very early in the study and is a matter of debate. The mechanisms involved in cardiovascular and renal benefits of empagliflozin are multifactorial. Hemodynamic effects, specifically reduced blood pressure and extracellular volume, driven by the direct drug class mechanism of action (osmotic diuresis), seems to be the main explanation for such a rapid effect, especially applied to the reduction in cardiovascular mortality and heart failure-related events. Many other factors including changes in weight, cardiac function, and metabolic actions could also be implied. A possible class effect should be confirmed in upcoming cardiovascular outcomes trials using other SGLT2 inhibitors. 
Table 1 Dosing and glomerular filtration rate cutoffs for SGLT2 inhibitors

\begin{tabular}{lcll}
\hline SGLT2 inhibitor & Dose $(\mathbf{m g})$ & $\begin{array}{l}\text { Glomerular filtration rate } \\
\text { cutoffs }\left(\mathbf{m L} / \mathbf{m i n} / \mathbf{1 . 7 3} \mathbf{~ m}^{\mathbf{2}}\right)\end{array}$ & Recommendation \\
\hline Dapagliflozin & 5 & $>60$ & No dose adjustment \\
& $10^{\mathrm{a}}$ & $<60$ & $\begin{array}{l}\text { Initial use is not recommended } \\
\text { Discontinue in patients already on treatment }\end{array}$ \\
& $<30$ & Contraindicated \\
Canagliflozin & 100 & $<30$ & Avoid \\
& 300 & $45-60$ & Use 100 mg dosing \\
& $<45$ & Discontinue in patients already on treatment \\
& $30-45$ & Initial use is not recommended \\
Empagliflozin & 10 & No dose adjustment \\
& 25 & $<45$ & Initial use is not recommended \\
& & Discontinue in patients already on treatment \\
& & Contraindicated \\
\hline
\end{tabular}

${ }^{a}$ In Europe dapagliflozin has only been commercialized as a dose of $10 \mathrm{mg}$

\section{ADVERSE EVENTS ASSOCIATED WITH SGLT2 AND CONCOMITANT THERAPIES}

The overall incidence of AEs using dapagliflozin, canagliflozin, or empagliflozin varies between $57.3 \%$ and $83.0 \%$ in different clinical trials, which is similar to other antidiabetic drugs (e.g., with metformin it ranges between $36.6 \%$ and $81.0 \%$ ) [15]. Most frequent AEs are infections of the genitourinary tract (including vulvovaginitis in women or balanitis in men), with a frequency between $3.6 \%$ and $9.0 \%$. Patients usually experience only a single episode, mild in intensity, and that responds to standard treatment [4].

SGLT2 inhibitors, when used in monotherapy, are associated with a low risk of hypoglycemia owing to their insulin-independent mechanism of action [7]. Additionally, longterm use of SGLT2 inhibitors has been associated with a rise in plasma glucagon levels and increased hepatic glucose production [16]. Interestingly, SGLT2-induced glucagon secretion is prevented by administering sulfonylureas concomitantly, thus explaining the risk of hypoglycemia with the use of these agents $[11,17-19]$. The frequency of hypoglycemia increases significantly when SGLT2 inhibitors are used with a background therapy that includes sulfonylureas [11, 17-19] or insulin [20-23], compared to placebo. Reported frequencies of hypoglycemia using SGLT2 inhibitors vary greatly, from $6.9 \%$ [11] to $43.2 \%$ [12] with sulfonylureas, and from $29.2 \%$ [20] to $60.4 \%$ [21] with insulin. AEs are more likely to occur during the first few days or weeks of treatment [24].

Reducing the insulin dose has also been associated with euglycemic diabetic ketoacidosis [25]. The US Food and Drug Administration (FDA) issued a warning in May 2015 about the potential risk of diabetic ketoacidosis in patients receiving SGLT2 inhibitors and, in February 2016, the European Medicines Agency (EMA) established recommendations to reduce the risk of diabetic ketoacidosis reported in these patients $[26,27]$. Nevertheless, the warning and recommendations come from case series with few patients, mainly those with type 1 diabetes who are insulin deficient [28]. To date, the cause of the higher frequency of diabetic ketoacidosis 
in patients with T2DM is unclear and requires further investigation. Recent studies have reported that SGLT2 inhibitors in pancreatic alpha cells trigger glucagon secretion [16]. The resulting hyperglucagonemia might contribute to ketogenesis under conditions of low insulin concentration. The osmotic diuresis induced by SGLT2 inhibitors can lead to dehydration, reduction in intravascular volume, and orthostatic hypotension.

The reported frequency of volume depletion-related events ranges between $1.2 \%$ and $1.5 \%[24,29]$. The risk of postural hypotension and dehydration is higher among patients receiving diuretics $(2.2-2.7 \%)$ than those who do not $(0.9-1.0 \%)[4,30]$. This risk is particularly increased when combined with thiazides and loop diuretics as a result of their mechanism of action, enhancing the removal of sodium and water. Patients over the age of 75 years have shown an up to $4.4 \%$ increased frequency of postural hypotension [20, 21, 31]. Gastrointestinal AEs, such as nausea, vomiting, and diarrhea, are main AEs of incretin drugs (DPP4 inhibitors and GLP-1 receptor agonists, GLP1ra), and metformin [32-34]. While in most cases these symptoms are intermittent and insidious, in some cases they can lead to dehydration and an added risk of SGLT2 therapy-associated volume depletion.

SGLT2 inhibitors might also affect bone metabolism given the increased number of bone fractures reported in some clinical trials [35]. Indeed, the FDA released a warning for the use of canagliflozin for this regard in 2005 $[36,37]$. Nevertheless, a recent meta-analysis of 38 randomized controlled trials (involving 30,384 patients, and a follow-up period between 24 and 160 weeks) has questioned the harmful effect of SGLT2 inhibitors on bone fractures [38]. A pooled analysis of 10 randomized trials has also suggested that the risk of fractures with canagliflozin might be caused by falls, potentially related to volume depletion-related AEs [39].

Furthermore, the FDA and EMA recently warned about a potential increased risk of lower limb amputation, mainly toes, in patients receiving canagliflozin [40,41]. This warning is based on the interim analysis of the ongoing
Canagliflozin Cardiovascular Assessment Study (CANVAS) clinical trial, in which the incidence of lower limb amputation was 7, 5, and 3 cases every 1000 patients with $100,300 \mathrm{mg}$ canagliflozin, and placebo, respectively. Further studies are required to corroborate the implication of SGLT2 inhibitors in bone fractures and lower limb amputations.

\section{MANAGEMENT WHEN INITIATING SGLT2 INHIBITORS}

\section{Suitable Patients}

SGLT2 inhibitors are effective at any stage of the natural history of T2DM owing to their insulin-independent mechanism of action. This fact supports their use as add-on therapy to any other antidiabetic agent, and as monotherapy in patients who are intolerant to metformin. However, the requirement of an adequate renal function and the development of AEs may limit their use. The patient profile that can most advantageously benefit from the properties of these drugs includes younger ages; estimated glomerular filtration rate at least $60 \mathrm{~mL} / \mathrm{min} /$ $1.73 \mathrm{~m}^{2}$ (renal function not impaired); established cardiovascular disease, no frequent genitourinary tract infections, overweight or obese; or hypertension (moderate to high blood pressure).

\section{Adjustment of Concomitant Therapies}

Lower doses of SGLT2 inhibitors are recommended when initiating treatment. It is also important to review concomitant therapies in order to minimize the risk of AEs. In the case of glucose-lowering therapies (insulin, sulfonylureas), the recommendation for patients with HbA1c less than $8.5 \%$ (less than $69 \mathrm{mmol} / \mathrm{mol}$ ) is to reduce their daily insulin dose by $20 \%$, with special caution to avoid insulin withdrawal to minimize the risk of euglycemic diabetic ketoacidosis (Fig. 2) [28, 31, 37, 42, 43]. Sulfonylureas should be reduced or stopped when initiating SGLT2 inhibitors. In contrast, maintaining the insulin dose is recommended for 
A

\begin{tabular}{|c|c|c|}
\hline \multicolumn{3}{|c|}{ Is the patient receiving an antidiabetic agent? } \\
\hline \multicolumn{2}{|c|}{$\sqrt{ }$} & $\downarrow$ \\
\hline \multicolumn{2}{|c|}{ SU or insulin } & Metformin or an \\
\hline$\downarrow$ & $\downarrow$ & Pla)? \\
\hline $\begin{array}{c}\mathrm{HbA} 1 \mathrm{c}<8.5 \% \\
(<69 \mathrm{mmol} / \mathrm{mol}) ?\end{array}$ & $\begin{array}{c}\mathrm{HbA} 1 \mathrm{c}>8.5 \% \\
(>69 \mathrm{mmol} / \mathrm{mol}) ?\end{array}$ & \\
\hline$\downarrow$ & $\downarrow$ & $\downarrow$ \\
\hline $\begin{array}{l}\text { SU: } \\
\text {-Reduce dose by } \\
50 \% \text { or stop* }\end{array}$ & $\begin{array}{l}\text { Su: } \\
\text {-Continue same } \\
\text { daily dose }\end{array}$ & $\begin{array}{l}\text { Continue same daily } \\
\text { dosage }\end{array}$ \\
\hline $\begin{array}{l}\text { Insulin: } \\
\text {-Reduce dose by } \\
20 \%^{*}\end{array}$ & $\begin{array}{l}\text { Insulin: } \\
\text {-Continue same } \\
\text { insulin dose }\end{array}$ & $\begin{array}{l}\text { If GI adverse events: } \\
\text { - Adjust dose of } \\
\text { metformin, DPP4i or } \\
\text { GLP1ra }\end{array}$ \\
\hline $\begin{array}{l}\text {-Adjust SU or } \\
\text { insulin dose as } \\
\text { needed based on } \\
\text { SMBG to prevent } \\
\text { hypoglycaemia }\end{array}$ & $\begin{array}{l}\text {-Adjust SU or } \\
\text { insulin dose as } \\
\text { needed based on } \\
\text { SMBG to prevent } \\
\text { hypoglycaemia }\end{array}$ & $\begin{array}{l}\text { - Ensure vigorous fluid } \\
\text { intake } \\
\text { - Monitor ketonuria or } \\
\text { ketonaemia (preferred) }\end{array}$ \\
\hline
\end{tabular}

B

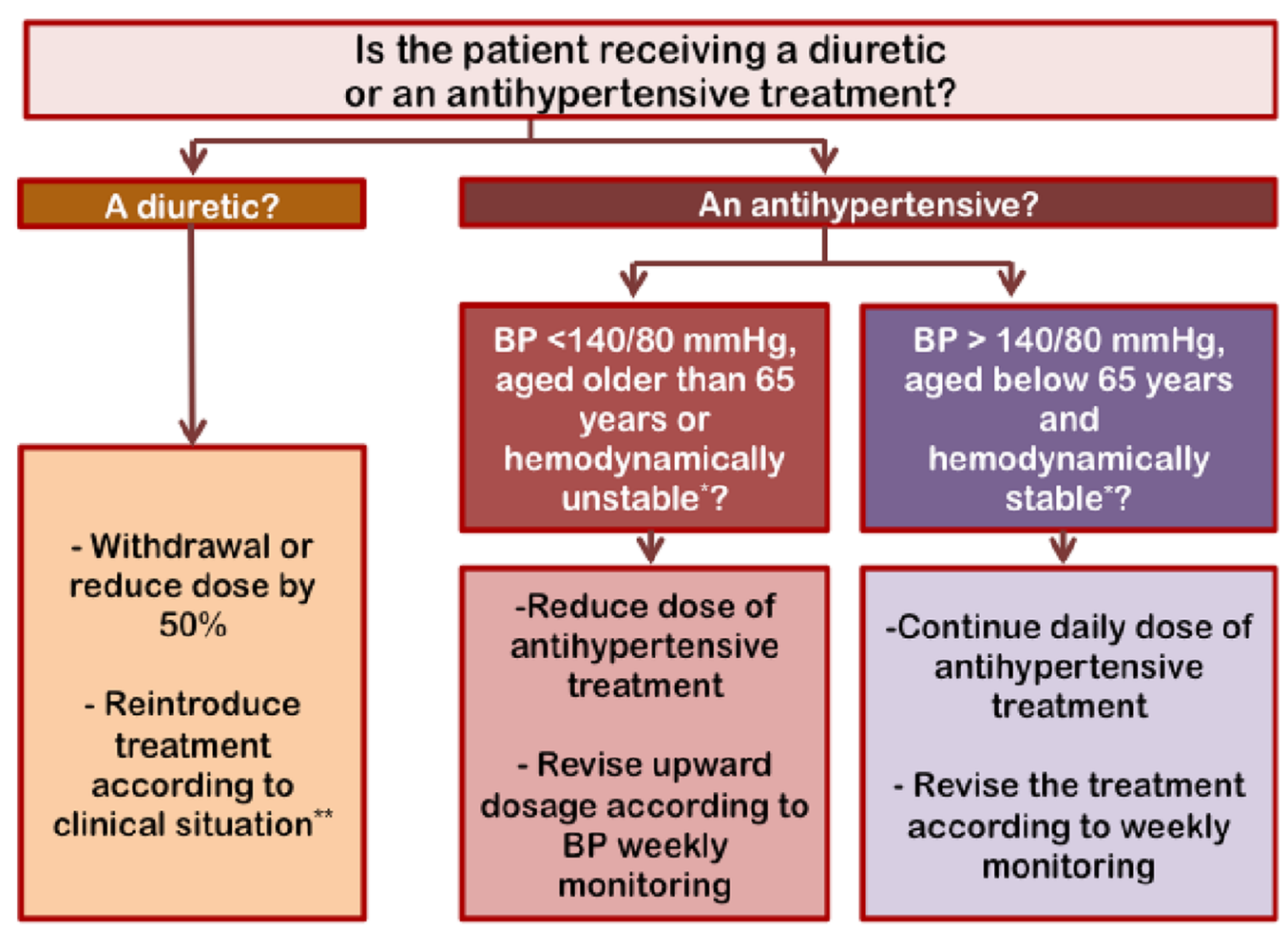


4Fig. 2 Proposed algorithm for adjusting antidiabetic agents (a) and diuretic/antihypertensive therapy (b) when initiating SGLT2 inhibitors in patients with type 2 diabetes. DPP4i DPP4 inhibitors, GI gastrointestinal, GLPIra GLP-1 receptor agonists, $S U$ sulfonylureas, $S M B G$ self-monitoring of blood glucose, $B P$ blood pressure. *Avoid insulin withdrawal to minimize the risk of euglycemic diabetic ketoacidosis. ${ }^{* *}$ Hemodynamically unstable defined as atrial fibrillation, orthostatic hypotension or blood pressure lability, prior syncope, etc. ${ }^{* * *}$ Clinical situation defined by congestive heart failure, edema, renal function

patients with $\mathrm{HbA1c}$ greater than $8.5 \%$ (greater than $69 \mathrm{mmol} / \mathrm{mol}$ ). In both cases, it is recommended that the patients self-monitor their blood glucose and adjust their insulin dose according to their glycemic control. Patients receiving metformin or an incretin-based therapy (DPP4 inhibitors, GLP1ra) should be especially monitored for the occurrence of gastrointestinal AEs. In the presence of vomiting or diarrhea, lowering the dose of metformin, DPP4 inhibitors/GLP1ra should be considered and vigorous fluid intake ensured. Ketonuria and/or ketonemia (preferred) monitoring is indicated in patients taking an SGLT2 inhibitor who present with symptoms suggestive of diabetic ketoacidosis, such as abdominal pain, nausea, vomiting, fatigue, and dyspnea [28]. When the concomitant therapy is a diuretic, recommendations include withdrawing the agent, and reconsidering the treatment according to the clinical situation, such as congestive heart failure, peripheral edema, or impaired renal function. In patients who are elderly and hemodynamically unstable (defined as the presence of atrial fibrillation, blood pressure lability, prior syncope), or with blood pressure under $140 / 80 \mathrm{mmHg}$, the recommendation is to decrease the antihypertensive treatment, and to review the treatment according to weekly monitoring. In contrast, in patients receiving antihypertensive treatment with high blood pressure who are hemodynamically stable, the recommendation is to maintain the antihypertensive treatment, and to review the treatment according to weekly monitoring.

\section{CONCLUSIONS}

SGLT2 inhibitors are an attractive novel therapeutic option for the treatment of T2DM. They block the reabsorption of filtered glucose, mainly in proximal renal tubules, resulting in increased urinary glucose excretion and correction of diabetes-related hyperglycemia. Beyond improving glucose control, SGLT2 inhibitors offer potential benefits by reducing body weight and blood pressure. On the basis of the efficacy demonstrated in clinical trials, SGLT2 inhibitors are recommended as second- or third-line agents for the management of patients with T2DM. Beneficial effects on kidney disease progression, cardiovascular and all-cause mortality, and hospitalization for heart failure have also been demonstrated with one SGLT2 inhibitor (empagliflozin). Potential AEs resulting from their mechanism of action (hypoglycemia and volume depletion-related events) make it advisable to review concomitant therapies when initiating with SGLT2 inhibitors. Although the overall frequency of AEs is relatively low among these patients, some individual characteristics (elderly, patients receiving diuretics, previous orthostatic hypotension, blood pressure lability, or prior syncope) may increase the risk of developing them.

\section{ACKNOWLEDGEMENTS}

Astra-Zeneca España contributed to support medical writing activities provided by Meysis S.L. No other external funding was received for this manuscript, which was written thanks to the unconditional effort of all authors. Responsibility for opinions, conclusions, and interpretation of data lies exclusively with the authors. The authors would like to thank to Pablo Vivanco Ph.D. of Meisys for helping in editorial assistance in the elaboration of the manuscript. All authors have met the International Committee of Medical Journal Editors (ICMJE) criteria for authorship of this manuscript and have given final approval for the version to be published. 
Financial disclosures. Albert Lecube Dr. Lecube has no relevant financial relationships to disclose.

Cristobal Morales Dr. Morales has no relevant financial relationships to disclose.

Miguel Brito-Sanifel Dr. Brito-Sanifel has no relevant financial relationships to disclose.

\section{Fernando Gomez-Peralta}

Research grant: Sanofi, Novo Nordisk, Boehringer Ingelheim, Ely Lilly.

Advisory board: Sanofi, Novo Nordisk, AZ.

Speakers' Bureau: Sanofi, Novo Nordisk, Boehringer Ingelheim, BMS, Ely Lilly, AZ.

\section{Alfonso Soto}

Research grant: Sanofi, Novo Nordisk, Boehringer Ingelheim, AZ, Novartis, Ely Lilly, GSK, Janssen-Cilag, Pfizer, Merck, Almirall.

Speakers' Bureau: Sanofi, Novo Nordisk, Boehringer Ingelheim, AZ, Novartis, Ely Lilly, GSK, Janssen-Cilag, Pfizer, Merck, Almirall.

\section{Cristina Abreu}

Research grant: Sanofi, Novo Nordisk, Boehringer Ingelheim, Ely Lilly.

Speakers' Bureau: Sanofi, Novo Nordisk, Boehringer Ingelheim, AZ, BMS.

\section{Diego Bellido}

Advisory board: Sanofi, Novo Nordisk, Boehringer Ingelheim.

Speakers' Bureau: Sanofi, Novo Nordisk, Boehringer Ingelheim, Novartis, Ely Lilly, AZ.

\section{Guillermo Umpierrez}

Research grant: Merck, Novo Nordisk, Boehringer Ingelheim.

Advisory board: Merck, Novo Nordisk, Boehringer Ingelheim, Regeneron.

Compliance with Ethics Guidelines. This article is based on previously conducted studies and does not involve any new studies of human or animal subjects performed by any of the authors.

Data Availability. Data sharing is not applicable to this article as no datasets were generated or analyzed during the current study.
Open Access. This article is distributed under the terms of the Creative Commons Attribution-NonCommercial 4.0 International License (http://creativecommons.org/licenses/ by-nc/4.0/), which permits any noncommercial use, distribution, and reproduction in any medium, provided you give appropriate credit to the original author(s) and the source, provide a link to the Creative Commons license, and indicate if changes were made.

\section{REFERENCES}

1. American Diabetes Association. Standards of medical care in diabetes-2017. Diabetes Care. 2017;40:S1-135.

2. Shah BR, Hux JE, Laupacis A, Zinman B, van Walraven $C$. Clinical inertia in response to inadequate glycemic control: do specialists differ from primary care physicians? Diabetes Care. 2005;28:600-6.

3. Inzucchi SE. Oral antihyperglycemic therapy for type 2 diabetes. JAMA. 2002;287:360-72.

4. Nauck MA. Update on developments with SGLT2 inhibitors in the management of type 2 diabetes. Drug Des Devel Ther. 2014;8:1335-80.

5. Fioretto P, Zambon A, Rossato M, Busetto L, Vettor R. SGLT2 inhibitors and the diabetic kidney. Diabetes Care. 2016;39:S165-71.

6. Bailey CJ, Gross JL, Pieters A, Bastien A, List JF. Effect of dapagliflozin in patients with type 2 diabetes who have inadequate glycaemic control with metformin: a randomized, double-blind, placebo-controlled trial. Lancet. 2010;375:2223-33.

7. Vasilakou D, Karagiannis T, Athanasiadou E, et al. Sodium-glucose cotransporter 2 inhibitors for type 2 diabetes: a systematic review and meta-analysis. Ann Intern Med. 2013;159:262-74.

8. Handelsman Y, Bloomgarden ZT, Grunberger G, et al. American Association of Clinical Endocrinologists and American College of Endocrinologyclinical practice guidelines for developing a diabetes mellitus comprehensive care plan-2015. Endocr Pract. 2015;21:1-87.

9. Hardy E, Salsali A, Hruba V, et al. Efficacy increases with increasing baseline HbA1c category with dapagliflozin therapy. Diabetes. 2012;61:23.

10. Bailey CJ, Morales Villegas EC, Woo V, Tang W, Ptaszynska A, List JF. Efficacy and safety of 
dapagliflozin monotherapy in people with type 2 diabetes: a randomized double-blind placebo-controlled 102-week trial. Diabet Med. 2015;32:531-41.

11. Häring HU, Merker L, Seewaldt-Becker E, et al. Empagliflozin as add-on to metformin plus sulfonylurea in patients with type 2 diabetes: a 24 -week, randomized, double-blind, placebo-controlled trial. Diabetes Care. 2013;36:3396-404.

12. Baker WL, Smyth LR, Riche DM, Bourret EM, Chamberlin KW, White WB. Effects of sodium-glucose co-transporter 2 inhibitors on blood pressure: a systematic review and meta-analysis. J Am Soc Hypertens. 2014;8(262-75):e9.

13. Zinman B, Lachin JM, Inzucchi SE. Empagliflozin, cardiovascular outcomes, and mortality in type 2 diabetes. N Engl J Med. 2016;374:1094.

14. Wanner C, Inzucchi SE, Lachin JM, et al. Empagliflozin and progression of kidney disease in type 2 diabetes. N Engl J Med. 2016;375:323-34.

15. Rossenwasser RF, Sultan S, Sutton D, Choksi R, Epstein BJ. SGLT-2 inhibitors and their potential in the treatment of diabetes. Diabetes Metab Syndr Obes. 2013;6:453-67.

16. Hattersley AT, Thorens B. Type 2 diabetes, SGLT2 inhibitors, and glucose secretion. N Engl J Med. 2015;373:974-6.

17. Strojek K, Yoon KH, Hruba V, Elze M, Langkilde AM, Parikh S. Effect of dapagliflozin in patients with type 2 diabetes who have inadequate glycaemic control with glimepiride: a randomized, 24-week, double-blind, placebo-controlled trial. Diabetes Obes Metab. 2011;13:928-38.

18. Schernthaner G, Gross JL, Rosenstock J, et al. Canagliflozin compared with sitagliptin for patients with type 2 diabetes who do not have adequate glycemic control with metformin plus sulfonylurea: a 52-week randomized trial. Diabetes Care. 2013;36:2508-15.

19. Matthaei S, Bowering K, Rohwedder K, Grohl A, Parikh S. Dapagliflozin improves glycemic control and reduces body weight as add-on therapy to metformin plus sulfonylurea: a 24-week randomized, double-blind clinical trial. Diabetes Care. 2015;38:365-72.

20. Wilding JP, Norwood P, T'joen C, Bastien A, List JF, Fiedorek FT. A study of dapagliflozin in patients with type 2 diabetes receiving high doses of insulin plus insulin sensitizers: applicability of a novel insulin-independent treatment. Diabetes Care. 2009;32:1656-62.

21. Wilding JP, Woo V, Soler NG, Sugg J, Rohwedder K, Parikh S. Long-term efficacy of dapagliflozin in patients with type 2 diabetes mellitus receiving high doses of insulin: a randomized trial. Ann Intern Med. 2012;156:405-15.

22. Rosenstock J, Jelaska A, Zeller C, Kim G, Broedl UC, Woerle HJ. Impact of empagliflozin added on to basal insulin in type 2 diabetes inadequately controlled on basal insulin: a 78-week randomized, double-blind, placebo-controlled trial. Diabetes Obes Metab. 2015;17:936-48.

23. Neal B, Perkovic V, De Zeeuw D, et al. Efficacy and safety of canagliflozin, an inhibitor of sodium-glucose cotransporter 2, when used in conjunction with insulin therapy in patients with type 2 diabetes. Diabetes Care. 2015;38:403-11.

24. Weir MR, Januszewicz A, Gilbert RE, et al. Effect of canagliflozin on blood pressure and adverse events related to osmotic diuresis and reduced intravascular volume in patients with type 2 diabetes mellitus. Diabetes Care. 2015;38:1687-93.

25. Peters AL, Buschur EO, Buse JB, Cohan P, Diner JC, Hirsch IB. Euglycemic diabetic ketoacidosis: a potential complication of treatment with sodium-glucose cotransporter 2 inhibition

26. US Food and Drug Administration. FDA Drug Safety Communication: FDA warns that SGLT2 inhibitors for diabetes may result in a serious condition of too much acid in the blood (05/15/2015). http://www. fda.gov/Drugs/DrugSafety/ucm446845.htm. Accessed March 2017.

27. European Medicines Agency. Meeting highlights from the Pharmacovigilance Risk Assessment Committee (PRAC). SGLT2 inhibitors: recommendations to minimise risk of diabetic ketoacidosis (8-11/02/2016). http://www.ema.europa.eu/ema/ index.jsp?curl=pages/medicines/human/referrals/SG LT2_inhibitors/human_referral_prac_000052.jsp\& mid =WC0b01ac05805c516f. Accessed March 2017.

28. Handelsman Y, Henry RR, Bloomgarden ZT, et al. American Association of Clinical Endocrinologists and American College of Endocrinology position statement on the association of SGLT-2 inhibitors and diabetic ketoacidosis. Endocr Pract. 2016;22:753-62.

29. Shubrook JH, Bokaie BB, Adkins SE. Empagliflozin in the treatment of type 2 diabetes: evidence to date. Drug Des Devel Ther. 2015;9:5793-803.

30. Liakos A, Karagiannis $\mathrm{T}$, Athanasiadou E, et al. Efficacy and safety of empagliflozin for type 2 diabetes: a systematic review and meta-analysis. Diabetes Obes Metab. 2014;16:984-93.

31. Nathan DM, Buse JB, Davidson MB, et al. Medical management of hyperglycemia in type 2 diabetes: a consensus algorithm for the initiation and 
adjustment of therapy: a consensus statement of the American Diabetes Association and the European Association for the Study of Diabetes. Diabetes Care. 2009;32:193-203.

32. Amori RE, Lau J, Pittas AG. Efficacy and safety of incretin therapy in type 2 diabetes: systematic review and meta-analysis. JAMA. 2007;298: 194-206.

33. Flórez H, Luo J, Castle-Florez Mitsi G, et al. Impact of metformin-induced gastrointestinal symptoms on quality of life and adherence in patients with type 2 diabetes. Postgrad Med. 2010;122:112-20.

34. Htike ZZ, Zaccardi F, Papamargaritis D, Webb DR, Khunti K, Davies MJ. Efficacy and safety of glucagon-like peptide- 1 receptor agonists in type 2 diabetes: a systematic review and mixed-treatment comparison analysis. Diabetes Obes Metab. 2017;19: 524-36.

35. Taylor SI, Blau JE, Rother KI. Possible adverse effects of SGLT2 inhibitors on bone. Lancet Diabetes Endocrinol. 2015;3:8-10.

36. US Food and Drug Administration. FDA Drug Safety Communication: FDA revises label of diabetes drug canagliflozin (Invokana, Invokamet) to include updates on bone fracture risk and new information on decreased bone mineral density. 2015. http:// www.fda.gov/Drugs/DrugSafety/ucm461449.htm. Accessed March 2017.

37. European Medicines Agency. Invokana brochure (canaglifozin). http://www.ema.europa.eu/docs/en_ GB/document_library/Referrals_document/SGLT2_ inhibitors_20/European_Commission_final_decision/ WC500206511.pdf. Accessed March 2017.
38. Tang HL, Li DD, Zhang JJ, et al. Lack of evidence for a harmful effect of sodium-glucose co-transporter 2 (SGLT2) inhibitors on fracture risk among T2DM patients: a network and cumulative meta-analysis of randomized controlled trials. Diabetes Obes Metab. 2016;18:1199-206.

39. Watts NB, Bilezikian JP, Usiskin K, et al. Effects of canagliflozin on fracture risk in patients with type 2 diabetes mellitus. J Clin Endocrinol Metab. 2016;101:157-66.

40. European Medicines Agency. SGLT2 inhibitors: information on potential risk of toe amputation to be included in prescribing information. http://www. ema.europa.eu/docs/en_GB/document_library/Press_ release/2017/02/WC500222191.pdf. Accessed March 2017.

41. US Food and Drug Adminstration. FDA Drug Safety Communication: interim clinical trial results find increased risk of leg and foot amputations, mostly affecting the toes, with the diabetes medicine canagliflozin (Invokana, Invokamet); FDA to investigate. https://www.fda.gov/Drugs/DrugSafety/ucm5009 65.htm. Accessed 11 March 2017.

42. European Medicines Agency. Farxiga brochure (dapaglifozin). http://www.ema.europa.eu/docs/en_GB/ document_library/EPAR_-_Product_Information/ human/002649/WC500156456.pdf. Accessed March 2017.

43. European Medicines Agency. Jardiance brochure (empagliflozin). http://www.ema.europa.eu/docs/ en_GB/document_library/Referrals_document/SGLT2 inhibitors_20/European_Commission_final_decision/ WC500206515.pdf. Accessed March 2017. 